\title{
Restless Leg Syndrome and Sleep Disorders in Patients with Rheumatoid Arthritis and Its Relation with Anemia Parameters
}

\author{
Salih Demir ${ }^{1}$, Adem Kucuk ${ }^{2, *}$, Mustafa Altas ${ }^{3}$, Erkan Cure ${ }^{4}$
}

\begin{abstract}
Objectives: We aimed to investigate the prevalence of restless legs syndrome (RLS) and sleep disorders in patients with rheumatoid arthritis (RA), and the association of iron deficiency with them.

Materials and methods: The study included 72 patients with RA ( 59 females, 13 males), and 50 healthy control subjects ( 57 females, 15 males). Assessments were made using the International RLS Rating Scale, Pittsburgh Sleep Quality Index (PSQI), Epworth Sleepiness Scale, Fatigue Severity Scale (FSS), Beck anxiety and depression index and the SF-36 quality of life scores. Results: We found that the frequency of RLS in RA patients was $29.1 \%$ and $13.8 \%$ in healthy control $(p=0.021)$. RA patients had $44.4 \%$ iron deficiency and $5.5 \%$ anemia of chronic disease. We found that $52.3 \%$ of patients with iron deficiency had RLS. There was an independent relationship between present of RLS and FSS (Beta $[\beta]=0.317, p=0.005)$ and total iron binding capacity $($ TIBC) $(\beta=0.244, p=0.031)$. There was an independent relationship between RLS severity score and PSQI $(\beta=0.264, p=0.025)$ and social functionality $(\beta=0.302, p=0.009)$. Conclusion: The prevalence of iron deficiency is high in RA in the developing countries. Analysis obtained in patients with RA is suggestive of an association between iron deficiency and increased frequency of RLS. The presence of RLS in patients with RA negatively affects sleep quality, psychiatric status, and quality of life of patients with RA. TIBC value may be a predictive marker for early detection of RLS in patients with RA.
\end{abstract}

\section{KEYWORDS}

rheumatoid arthritis; restless legs syndrome; sleep disorders; iron deficiency; total iron binding capacity

\section{AUTHOR AFFILIATIONS}

${ }^{1}$ Department of Internal Medicine, Necmettin Erbakan University, Konya, Turkey

2 Division of Rheumatology, Department of Internal Medicine, Necmettin Erbakan University, Konya, Turkey

${ }^{3}$ Department of Neurology, Necmettin Erbakan University, Konya, Turkey

${ }^{4}$ Department of Internal Medicine, Ota \& Jinemed Hospital, Istanbul, Turkey

* Corresponding author: Division of Rheumatology, Department of Internal Medicine, Necmettin Erbakan University, Konya, Turkey; e-mail: drademk@yahoo.com

Received: 21 January 2021

Accepted: 15 May 2021

Published online: 11 November 2021

Acta Medica (Hradec Králové) 2021; 64(3): 137-144

https://doi.org/10.14712/18059694.2021.24

(c) 2021 The Authors. This is an open-access article distributed under the terms of the Creative Commons Attribution License (http://creativecommons.org/licenses/by/4.0), which permits unrestricted use, distribution, and reproduction in any medium, provided the original author and source are credited. 


\section{INTRODUCTION}

Rheumatoid arthritis (RA) affects approximately $0.5 \%$ to $1 \%$ of the population worldwide (1). RA is a systemic, chronic autoimmune disease that symmetrically leads to arthritis in the joints. Environmental and genetic factors play a role in the pathogenesis of RA, and its etiology is unclear $(1,2)$. It is three to four times more common in women than in men. In RA, patients may develop joint deformities, loss of function, and workforce loss due to bone erosions (1,2). RA can affect the central and peripheral nervous system and many organs. Anemia is common in patients with RA and has multifactorial pathogenesis (3). Although most types of anemia can be seen in RA patients, iron deficiency anemia (IDA) and anemia of chronic disease (ACD) are common (3). In patients with RA, IDA is mostly caused by chronic blood loss from the gastrointestinal tract due to gastritis (due to the use of non-steroidal anti-inflammatory drugs), peptic ulcer, or diaphragmatic hernia. Most patients with IDA are asymptomatic (4).

The psychological effects of RA can be seen in many areas of life such as family life and social relationships, therefore, it can lead to mood disorders (5). These mood disorders can cause pain, increased disease activity, cytokine release, immune-modulatory responses, and sleep disorders in patients. The sleep structure is usually normal, but sleep is interrupted with increased arousals and movements during sleep (6). Studies have reported that sleep disturbance and difficulty maintaining sleeping are seen in $50-75 \%$ (7).

Restless leg syndrome (RLS) is a common disease associated with chronic, sensorimotor motion disorder, especially holding the lower limb (8). In this syndrome, especially in the period when the patient is inactive, such as evening and night, paresthesia and restlessness occur. The patient is partially or completely relaxed with movement (8). Although RLS pathophysiology is not fully understood, dopamine dysfunction and a decrease of cerebral iron and ferritin levels play a critical role in the central nervous system (9). RLS is a common disease accompanying RA. The patient's quality of life can be improved by rapid diagnosis and treatment of RLS (10).

Several studies in the literature have proven the presence of RLS in patients with RA (10-14). In this study, we aimed to show the frequency of IDA and the relationship of iron deficiency with RLS in RA patients. Second, we aimed to investigate the effects of RLS on sleep disorder, psychological conditions, and quality of life in RA.

\section{MATERIAL AND METHOD}

Seventy-two patients diagnosed as RA according to ACR/ EULAR 2010 Rheumatoid Arthritis Classification Criteria (15) and followed up in our hospital's Rheumatology Outpatient Clinic were included in the study. Seventy-two healthy people with sociodemographic characteristics similar to the group of patients without known systemic disease were included in the study as a control group. Patients with known liver, kidney, thyroid disease, hypertension, diabetes mellitus, other systemic connective tissue diseases, malignancy, chronic neurological disease, preg- nancy, alcohol dependence were excluded in the study. The patient and the control group were interviewed face-toface and evaluated for RLS symptoms. Patients who ensure four of the following criteria recommended by the International Working Group were diagnosed with RLS: (i) the urge to move limbs with senses of paresthesia/dysesthesia; (ii) the need to move and feel relaxed when moving; (iii) exacerbation of symptoms while resting and relief of symptoms when moving; (iv) exacerbation of symptoms in the evening/night. The severity of RLS was determined using the IRLSSG-RS scale in both groups $(16,17)$.

\section{BECK DEPRESSION INVENTORY (BDI)}

Depression levels were evaluated with the BDI comprising 21 items ranging from 0 to 3 . The highest score is 63 . One of the most commonly used self-rated depression scales, BDI is adaptable to any age group and considered highly reliable (18).

\section{BECK ANXIETY INVENTORY (BAI)}

BAI is a Likert-type self-report inventory applied to determine the prevalence and intensity of anxiety symptoms experienced by the individual. The BAI scale tests subjective anxiety and somatic symptoms such as dizziness, difficulty breathing, dizziness, flushing, and heartbeat. The highest score that can be obtained from this test is 63 and covers 21 symptoms (19).

\section{FATIGUE SEVERITY SCALE}

FSS is a questionnaire comprising 9 questions in total. Fatigue severity is assessed in different situations during the past week. Items are scored on a 7-point scale. $1=$ strongly disagree and $7=$ strongly agree. The average FSS score is found by dividing the total score by 9 . The score is interpreted as $\geq 4$ fatigue. Higher scores show a higher level of fatigue (20).

\section{PITTSBURGH SLEEP QUALITY INDEX (PSQI)}

PSQI is used to assess sleep quality for 1 month. Includes nineteen separate items and seven component points; by collecting these points, a general score between 0 and 21 is obtained. Higher scores represent subjective sleep quality disorder. PSQI score $>5$ is considered sleep disturbance (21).

\section{EPWORTH SLEEPINESS SCALE (ESS)}

The ESS which includes eight items related to falling asleep or sleepiness in eight different daily living activities is used to assess daytime sleepiness. The ESS score ranges from 0 to 24, and higher scores show more be sleep state during the day (22).

\section{6-ITEM SHORT-FORM HEALTH SURVEY (SF-36) QUESTIONNAIRE}

SF-36 is a general health-related quality-of-life questionnaire used to score for eight subscales, including physical 
function, role-physical, role-emotional, social functionality, general health, mental health, vitality, and physical pain. These subscales are combined to create two high-level summaries called physical and mental health component summaries (23).

\section{ETHICAL ISSUE}

Before the study, the voluntary patient consent form was obtained from the patient and control groups. We obtained approval for the study from the local ethics committee (2019/1823).

\section{BIOCHEMICAL PARAMETERS}

Venous blood samples from both patients and the control group were collected after 10 to 12 hours of fasting. Glucose blood urea nitrogen, creatinine, lipid panel, and ALT were studied with the photometric method of the Abbott Architect C16000 analyzer. C-reactive protein (CRP) was studied with the nephelometric method of Coulter Immage 800 device. HDL was analyzed using a direct enzymatic method without precipitation. Hematological tests were analyzed by the Abbott Cell Dyn Ruby analyzer. Erythrocyte sedimentation rate (ESR) was analyzed with the automated device Westerr (Eventus vacuplus ES 100).
The diagnosis of IDA and ACD was made according to the current guideline. According to the hemoglobin, ferritin, and transferrin saturation values, the patients and the control group were divided into three groups as IDA, ACD, and normal (24).

\section{STATISTICAL ANALYSIS}

All statistical analyzes were done with SPSS 20 program. Results are given as mean \pm standard deviation, median (minimum-maximum), and $\mathrm{n}$ (percent). Whether the groups showed homogeneous distribution was evaluated with the Kolmogorov-Smirnov Test. Data showing homogenous distribution were evaluated by Student T-Test and non-homogeneous data were evaluated by Mann Whitney U Test. Categorical data were analyzed with Chi-square test. Pearson correlation test and Spearman Rank test were used for correlation analysis. Independent variables affecting the RLS severity score were analyzed by linear regression analysis. A p-value $<0.05$ was considered significant.

\section{RESULTS}

Age $(51.9 \pm 11.4$ vs $49.5 \pm 11.2$ years, $\mathrm{p}=0.215)$, gender $(\mathrm{F} / \mathrm{M}$ : $59 / 13$ vs $57 / 15, \mathrm{p}=0.417)$, and body mass index (29.0 \pm 5.5 vs

Tab. 1 Sociodemographic data of the patient and control groups.

\begin{tabular}{|c|c|c|c|}
\hline Parameters & $\mathrm{RA}(\mathrm{n}=72)$ & Control $(n=72)$ & P value \\
\hline Age (years) (mean \pm SD) & $51.9 \pm 11.4$ & $49.5 \pm 11.2$ & 0.215 \\
\hline Gender (F/M) (n) & $59 / 13$ & $57 / 15$ & 0.417 \\
\hline $\mathrm{BMI}\left(\mathrm{kg} / \mathrm{m}^{2}\right)($ mean $\pm \mathrm{SD})$ & $29.0 \pm 5.5$ & $29.0 \pm 4.9$ & 0.941 \\
\hline DASH-28 & $2.8 \pm 1.0$ & & \\
\hline Anti-CCP + (n, \%) & $40(55.6)$ & 0 & \\
\hline$R F+(n, \%)$ & $37(51.4)$ & 0 & \\
\hline Disease duration (years) & $3(1-18)$ & & \\
\hline Smoking (n) & 8 & 16 & 0.016 \\
\hline Drinking (n) & 0 & 2 & 0.248 \\
\hline Hypertension (n) & 23 & 16 & 0.130 \\
\hline Osteoporosis (n) & 2 & 1 & 0.500 \\
\hline Hydroxychloroquine (n) & 39 & & \\
\hline Steroid (n) & 31 & & \\
\hline Methotrexate (n) & 37 & & \\
\hline NSAIDs (n) & 12 & 3 & 0.012 \\
\hline Leflunomide (n) & 25 & & \\
\hline Salazopyrin (n) & 27 & & \\
\hline Infliximab (n) & 1 & & \\
\hline Etanercept (n) & 0 & & \\
\hline Golimumab (n) & 4 & & \\
\hline Certolizumab (n) & 2 & & \\
\hline Tocilizumab (n) & 7 & & \\
\hline Rituximab (n) & 1 & & \\
\hline
\end{tabular}

Abbreviations: Ra, rheumatoid arthritis; F, female; M, male; BMI, body mass index; DASH-28, The Disease Activity Score-28 for Rheumatoid Arthritis; Anti-CCP, anti-cyclic citrullinated peptide; RF, rheumatoid factor; NSAIDs, non-selective non-steroidal anti-inflammatory agents. 
$\left.29.0 \pm 4.9 \mathrm{~kg} / \mathrm{m}^{2}, \mathrm{p}=0.941\right)$ values of patients with RA were similar to the control group. Anti-CCP was positive in $55.6 \%$ of patients and $\mathrm{RF}$ was positive in $51.4 \%$ of patients. While $15(20.8 \%)$ of the patients were using biological agents, the remaining patients were receiving DMARD therapy. All sociodemographic characteristics of the patients are given in Table 1.

The hemoglobin level of the patients $(p=0.011)$ was significantly lower than the control group. The patients' iron level $(68.9 \pm 36.1$ vs $78.6 \pm 34.3)$ was lower than the control group, but not significant. The ferritin (53.3 [4.0-655.0] vs $45.7[2.0-432.0]$ ) and total iron-binding capacity (TIBC) $(266.4 \pm 73.5$ vs $261.2 \pm 71.3)$ values of the patients were similar to the ferritin and TIBC values of the control group. The Vitamin D level $(18.0 \pm 8.8$ vs $14.3 \pm 8.2, \mathrm{p}=0.009)$ of the RA group was higher than the control group. ESR, and $C R P$ values of RA patients were higher than the control group. The albumin value of RA patients was lower than the control group. All laboratory results of the patients are seen in Table 2.
Thirty-two patients had IDA, and 11 of them had RLS. Four patients had ACD, and 1 of them had RLS. In the control group, seventeen individuals had IDA, and 4 of them had RLS. Four of 10 RLS individuals had IDA (Figure 1).

The numbers of RLS positive patients were 2 -fold more than the control group ( $29.1 \%$ vs $13.8 \%, p=0.021)$. The RLS severity scale of both groups was similar. ESS was slightly higher in the RA group than control but were not significant. The PSQI value of the RA group was significantly higher than the control group. BAI and BDI values of RA patients were significantly higher than the control group. Physician visual analogue scales (VAS) and patient VAS values of the patient group were significantly lower than the control group. In the patient group, SF-36's physical function, physical role, vitality, social function, pain, general health perception scores were significantly lower than the control group. The emotional role, mental health, and health status change values of SF-36 in the patient group were also lower than the control group. But it was not statistically significant. All results and $\mathrm{p}$ values are seen in Table 3.

Tab. 2 Biochemical results of the patient and control groups.

\begin{tabular}{|c|c|c|c|}
\hline Parameters & $R A(n=72)$ & Control $(n=72)$ & P value \\
\hline WBC (×109/L) & $7.7 \pm 3.6$ & $7.8 \pm 2.1$ & 0.852 \\
\hline Neutrophils & $4.8 \pm 3.0$ & $4.6 \pm 1.7$ & 0.757 \\
\hline Lymphocytes & $2.1 \pm 0.8$ & $2.3 \pm 0.7$ & 0.042 \\
\hline Hemoglobin (g/dL) & $12.7 \pm 1.7$ & $13.5 \pm 1.7$ & 0.011 \\
\hline RDW & $14.6 \pm 2.1$ & $13.6 \pm 1.6$ & 0.001 \\
\hline Platelets (×109/L) & $294.1 \pm 78.9$ & $280.9 \pm 75.5$ & 0.272 \\
\hline $\mathrm{CRP}(\mathrm{mg} / \mathrm{dL})$ & $4.1(0.5-96.0)$ & $3.1(0.5-37.0)$ & 0.021 \\
\hline $\operatorname{ESR}(\mathrm{mm} / \mathrm{h})$ & $16.5(2.0-72.0)$ & $11.0(2.0-48.0)$ & 0.007 \\
\hline FPG (mg/dL) & $97.4 \pm 13.9$ & $99.6 \pm 16.6$ & 0.380 \\
\hline Creatinine (mg/dL) & $0.70 \pm 0.1$ & $0.74 \pm 0.1$ & 0.152 \\
\hline Sodium (mEq/L) & $140.4 \pm 2.3$ & $140.0 \pm 1.7$ & 0.318 \\
\hline Potassium (mEq/L) & $4.4 \pm 0.5$ & $4.4 \pm 0.4$ & 0.709 \\
\hline Calcium (mg/dL) & $9.3 \pm 0.4$ & $9.4 \pm 0.4$ & 0.135 \\
\hline Total cholesterol (mg/dL) & $183.4 \pm 40.2$ & $185.6 \pm 41.0$ & 0.742 \\
\hline Triglyceride (mg/dL) & $144.6 \pm 84.9$ & $144.6 \pm 72.0$ & 0.999 \\
\hline $\mathrm{HDL}(\mathrm{mg} / \mathrm{dL})$ & $52.1 \pm 16.1$ & $48.4 \pm 12.3$ & 0.122 \\
\hline $\mathrm{LDL}(\mathrm{mg} / \mathrm{dL})$ & $101.5 \pm 32.2$ & $106.2 \pm 36.4$ & 0.413 \\
\hline Albumin (g/dL) & $4.2 \pm 0.3$ & $4.4 \pm 0.3$ & 0.001 \\
\hline AST (IU/L) & $17.3 \pm 7.6$ & $16.4 \pm 6.1$ & 0.447 \\
\hline ALT (IU/L) & $18.8 \pm 9.4$ & $18.7 \pm 8.8$ & 0.934 \\
\hline Iron $((\mu \mathrm{g} / \mathrm{dl})$ & $68.9 \pm 36.1$ & $78.6 \pm 34.3$ & 0.099 \\
\hline TIBC (ug/dL) & $266.4 \pm 73.5$ & $261.2 \pm 71.3$ & 0.663 \\
\hline Ferritin (ng/ml) & $53.3(4.0-655.0)$ & $45.7(2.0-432.0)$ & 0.876 \\
\hline Transferrin saturation (\%) & $29.8 \pm 22.4$ & $34.0 \pm 20.3$ & 0.249 \\
\hline TSH (mU/L) & $1.9 \pm 1.2$ & $1.9 \pm 1.0$ & 0.978 \\
\hline Vitamin $B_{12}(p g / m L)$ & $378.4 \pm 207.5$ & $341.3 \pm 169.5$ & 0.242 \\
\hline Folic acid (ng/ml) & $9.0 \pm 4.3$ & $8.4 \pm 3.6$ & 0.395 \\
\hline Vitamin D (ng/mL) & $18.0 \pm 8.8$ & $14.3 \pm 8.2$ & 0.009 \\
\hline
\end{tabular}

Abbreviations: RA, rheumatoid arthritis; WBC, white blood cell count; RDW, red blood cell distribution width; CRP, C-reactive protein; ESR, erythrocyte sedimentation rate; FPG, fasting plasma glucose; HDL, high density lipoprotein; LDL, low-density lipoprotein; AST, aspartate aminotransferase; ALT, alanine aminotransferase; TIBC, total iron binding capacity; TSH, thyroid stimulating hormone. 


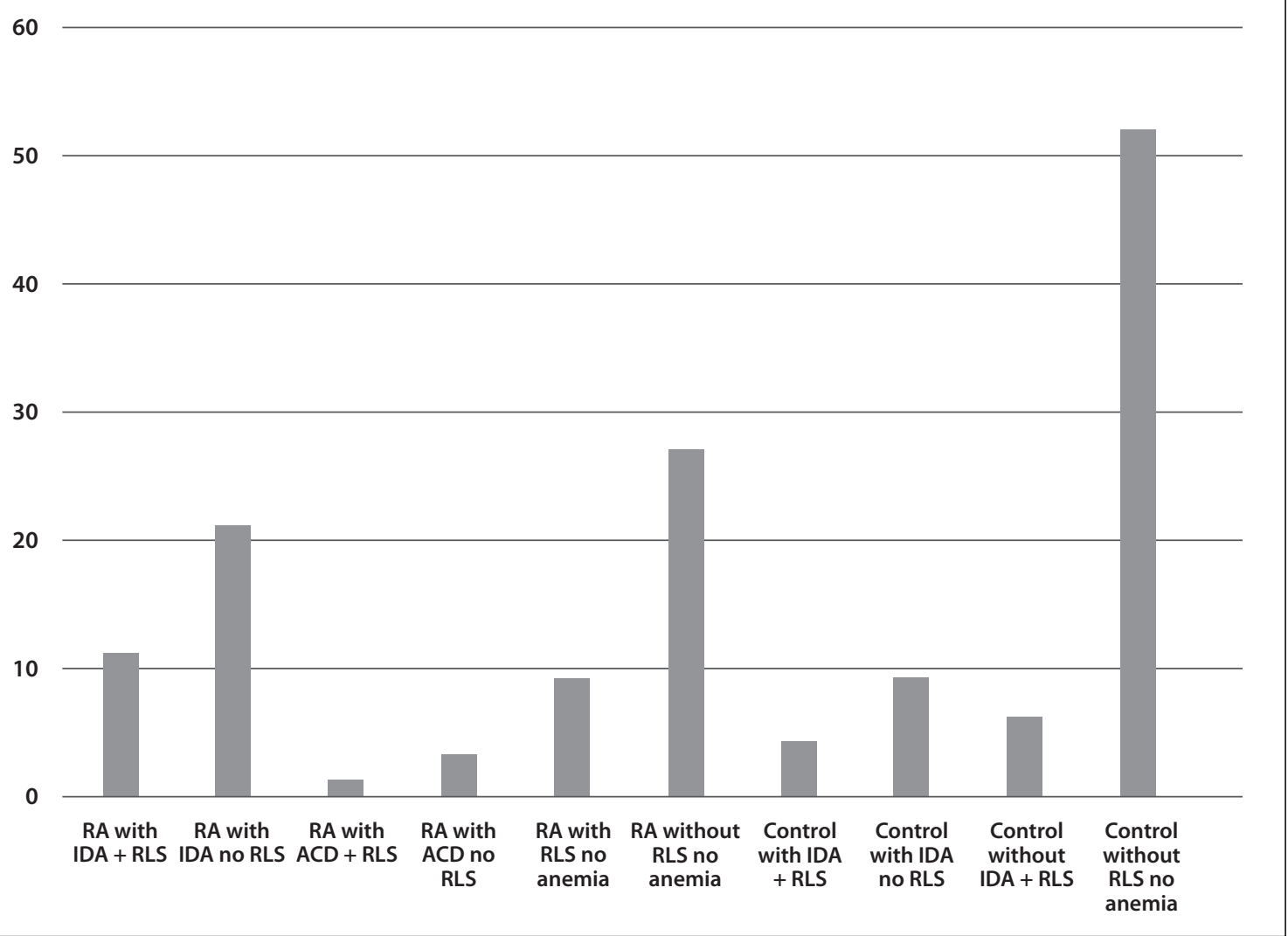

Fig. 1 Prevalence of RLS in RA patients with and without anemia.

Tab. 3 Evaluation of sleep and life quality of patient and control groups.

\begin{tabular}{|c|c|c|c|}
\hline Parameters & RA $(n=72)$ & Control $(n=72)$ & $P$ value \\
\hline $\operatorname{RLS}(n, \%)$ & $21(29.1)$ & $10(13.8)$ & 0.021 \\
\hline RLS (F/M) & $17 / 4$ & $8 / 0$ & 0.188 \\
\hline RLS severity score & $12.5 \pm 5.2$ & $13.1 \pm 6.4$ & 0.830 \\
\hline ESS & $5.3 \pm 3.2$ & $4.4 \pm 3.4$ & 0.141 \\
\hline PSQI & $6.5 \pm 3.5$ & $4.3 \pm 3.0$ & $<0.001$ \\
\hline $\mathrm{PSQI} \geq 5, \mathrm{n}(\%)$ & $43(59.7)$ & $23(31.9)$ & 0.001 \\
\hline ISI & $9.0(2.0-20.0)$ & $2.0(0.0-16.0)$ & 0.001 \\
\hline FSS & $3.3 \pm 1.5$ & $2.8 \pm 1.6$ & 0.094 \\
\hline BAI & $8.5 \pm 5.7$ & $6.1 \pm 4.8$ & 0.008 \\
\hline BDI & $9.7 \pm 6.0$ & $7.0 \pm 5.6$ & 0.007 \\
\hline Physical functioning & $61.6 \pm 21.2$ & $75.9 \pm 22.8$ & $<0.001$ \\
\hline Role physical & $43.4 \pm 41.5$ & $63.1 \pm 44.7$ & 0.007 \\
\hline Role emotional & $74.7 \pm 32.1$ & $83.4 \pm 32.2$ & 0.108 \\
\hline Vitality & $45.6 \pm 13.7$ & $50.2 \pm 14.3$ & 0.049 \\
\hline Mental health & $58.8 \pm 10.0$ & $61.7 \pm 9.9$ & 0.086 \\
\hline Social functioning & $80.6 \pm 19.7$ & $89.5 \pm 15.4$ & 0.003 \\
\hline Bodily pain & $68.8 \pm 21.5$ & $78.8 \pm 24.2$ & 0.010 \\
\hline General health & $39.2 \pm 16.1$ & $47.1 \pm 18.6$ & 0.007 \\
\hline Change observed in health & $45.2 \pm 19.3$ & $48.0 \pm 25.1$ & 0.458 \\
\hline Physician VAS & $2.3 \pm 1.4$ & $1.2 \pm 0.9$ & $<0.001$ \\
\hline Patients VAS & $3.1 \pm 1.5$ & $1.8 \pm 1.2$ & $<0.001$ \\
\hline
\end{tabular}

Abbreviations: RA, rheumatoid arthritis; RLS, restless leg syndrome; ESS, Epworth Sleepiness Scale; PSQI, Pittsburgh Sleep Quality Index; ISI, Insomnia Severity Index; FSS, Fatigue Severity Scale; BAI, beck anxiety inventory; BDI, Beck Depression Index; VAS, visual analogue scale. 
When correlation analysis was performed in the patient group, we found that the RLS severity score was positively associated with PSQI, Insomnia Severity Index, Fatigue Severity Scale, BAI, BDI, pain, and TIBC values. We found a negative correlation between the RLS severity score and energy/vitality, mental health, and social functionality. Correlation analysis results are seen in Table 4.

Tab. 4 Correlation analysis results of patients.

\begin{tabular}{|l|c|c|}
\hline Parameters & \multicolumn{2}{|c|}{ RLS severity score } \\
\hline PSQI & rvalue & p value \\
\hline ISI & 0.456 & 0.001 \\
\hline FSS & 0.367 & 0.003 \\
\hline BAI & 0.431 & 0.001 \\
\hline BDI & 0.430 & $<0.001$ \\
\hline Vitality & 0.339 & 0.006 \\
\hline Mental health & -0.389 & 0.001 \\
\hline Social functioning & -0.266 & 0.033 \\
\hline Bodily pain & -0.412 & 0.001 \\
\hline TIBC & 0.291 & 0.018 \\
\hline
\end{tabular}

Abbreviations: RLS, restless leg syndrome; PSQI, Pittsburgh Sleep Quality Index; ISI, Insomnia Severity Index; Fatigue Severity Scale; BAI, beck anxiety inventory; BDI, beck depression inventory; TIBC, total iron binding capacity.

In the multivariate regression analysis, there was an independent relationship between present of RLS and fatigue severity scale (Beta $[\beta]=0.317, p=0.005)$ and TIBC $(\beta=$ $0.244, p=0.031)$. There was an independent relationship between RLS severity score and PSQI $(\beta=0.264, p=0.025)$ and social functionality $(\beta=0.302, \mathrm{p}=0.009)$ (Table 5$)$.

Tab. 5 Stepwise linear regression analysis.

\begin{tabular}{|l|c|c|c|}
\hline $\begin{array}{l}\text { Dependent } \\
\text { variable }\end{array}$ & $\begin{array}{c}\text { Independent } \\
\text { Variables }\end{array}$ & $\begin{array}{c}\text { Beta regression } \\
\text { coefficient }\end{array}$ & P value \\
\hline RLS & FSS & 0.317 & 0.005 \\
\hline TIBC & 0.244 & 0.031 \\
\hline $\begin{array}{l}\text { RLS severity } \\
\text { score }\end{array}$ & PSQI & 0.366 & 0.002 \\
\hline & $\begin{array}{c}\text { Social } \\
\text { functioning }\end{array}$ & 0.302 & 0.009 \\
\hline
\end{tabular}

Abbreviations: RLS, restless leg syndrome; FSS, Fatigue Severity Scale; TIBC, Total iron binding capacity; PSQI, Pittsburgh Sleep Quality Index.

\section{DISCUSSION}

In several studies, the frequency of RLS in RA patients was between $20-30 \%$, and in healthy controls was found between $2-10 \%(10,13,14,25)$. In our study, we found that the frequency of RLS in RA patients was $29.1 \%$ and $13.8 \%$ in healthy control. In the literature, only one study reported the frequency of RLS in RA as 63\% (12). Since both diseases are more common in women, RLS is expected to be more common in female RA patients. Previous studies and our study reveal that RLS is more common in female RA patients (25).

RLS is also associated with other rheumatological diseases. The frequency of RLS was reported as $30.6 \%$ in systemic lupus erythematosus (SLE), $29.4 \%$ in Behçet's disease, $30.8 \%$ in ankylosing spondylitis, $40.7 \%$ in systemic sclerosis, and $64 \%$ in psoriatic arthritis $(8,26)$. RLS is often associated with immune-based diseases such as Crohn, multiple sclerosis, psoriasis. In autoimmune diseases that damage the dopaminergic system such as Parkinson and SLE, the frequency of RLS has been reported to increase $(27,28)$. Previous studies suggest that symptoms in RLS patients occur because of damage to the dopaminergic pathway. In RLS patients, dopamine receptor agonists significantly relieve the patients' clinic (26-28). A better-known mechanism in RLS etiology is iron deficiency. The low iron level in the serum leads to an increase in the extracellular dopamine level, thereby reducing D2 dopaminergic receptors in the brain tissue (29). The formation of levodopa from tyrosine is catalyzed by the tyrosine hydroxylase enzyme, and this step is the rate-limiting step in dopamine synthesis. In iron deficiency, dopamine synthesis is reduced (30).

RA is a chronic inflammatory disease. Chronic inflammation causes iron to be trapped in macrophages and reduced iron supply to the bone marrow. A previous study reported the frequency of IDA in RA patients with RLS was $4.7 \%$ and the frequency of other anemia types was $3.1 \%$ (25). The frequency of IDA in patients with RA is between $30-60 \%$ in developing countries (4). Our RA patients had $44.4 \%$ IDA and $5.5 \%$ ACD. We found that $52.3 \%$ of patients with IDA had RLS and $25 \%$ of patients with ACD had RLS. When patients with both IDA and ACD were examined together, $57.1 \%$ of RA patients with RLS had anemia. In the current study, the control group had 23.6\% IDA and individuals with IDA had $23.5 \%$ RLS. In the control group, $25 \%$ of individuals with RLS had DEA. While the TIBC level of our patients was like the control group, the iron level was lower than the control group. Although the ferritin values of our patients were not statistically significant, they were slightly higher than the control group. Ferritin is an acutephase reactant. The ferritin values of our patients may be higher due to chronic inflammation than healthy control. Ferritin may not always be a good marker in demonstrating iron deficiency (24). Transferrin saturation is a more specific marker than ferritin in demonstrating iron deficiency (24). It is obtained by dividing the serum iron value by the serum TIBC value. TIBC increase alone is a strong marker in diagnosing IDA (31). In the regression analysis, we found an independent relationship between TIBC and RLS scores. In RA patients, TIBC can be a strong marker for the RLS severity score.

Vitamin $D$ is an immune-modulating vitamin. Vitamin $D$ is known to protect dopaminergic neurons against toxic substances. Therefore, vitamin D deficiency has been associated with RLS (32). In our study, vitamin D levels of RA patients were lower than normal, but higher than the control group. The relationship between RA and vitamin 
D deficiency is known (33). We did not have any patients using vitamin D supplements; however, most RA patients may receive vitamin $D$ therapy intermittently. It has been reported that vitamin $\mathrm{D}$ treatment does not improve RLS symptoms (34). We did not find a significant relationship between RLS and vitamin $D$ in regression analysis.

Since RA is a disease with inflammation, many pro-inflammatory cytokine levels such as interleukin (IL)-1, IL-6, and tumor necrosis factor (TNF)-alpha an increase in RA patients (2). Some cytokines such as IL-4, IL-10, IL-13, and transforming growth factor (TGF)-beta have been reported to adversely affect the non-REM sleep phase and lead to sleep disturbance (35). Some cytokines, such as TNF-alpha, show the diurnal rhythm. In RA patients, improvement of sleep quality with TNF-alpha blockade suggests that TNF-alpha and other pro-inflammatory cytokines are responsible for sleep disturbance (36). Previous studies have reported between $62-63 \%$ sleep disturbance in RA patient's disturbance $(12,36)$. We found that $59.7 \%$ of our patients had sleep quality impairment. In the correlation analysis, we found a strong relationship between RLS score and PSQI, insomnia severity index, FSS, and vitality.

The presence of anxiety and depression in RA patients has been reported in the literature (37). RA is associated with psychological disorders due to pain, physical disabilities, and restricting one's work, family, and social life. This results in anxiety, depression, and a sense of helplessness. Depression and anxiety are psychiatric disorders frequently seen in RA (38). Quality of life disorder, anxiety, and depression are also associated with RLS (39). In the correlation analysis, we found a strong relationship between RLS score and BAI and BDI tests. We also found a negative relationship between the RLS severity score and mental health, social functionality, and pain. According to our results, RA and RLS coexistence significantly affect patients with RA psychologically and socially.

\section{CONCLUSION}

The prevalence of IDA is high in patients with RA in developing countries. Analysis obtained in patients with RA is suggestive of an association between iron deficiency and increased frequency of RLS. The presence of RLS in patients with RA negatively affects sleep quality, psychiatric status, and quality of life of patients with RA. TIBC value may be a predictive marker for early detection of RLS in patients with RA.

\section{REFERENCES}

1. Gibofsky A. Overview of epidemiology, pathophysiology, and diagnosis of rheumatoid arthritis. Am J Manag Care 2012; 18: S295-S302.

2. Tuzcu A, Baykara RA, Omma A, et al. Thiol/Disulfide homeostasis in patients with rheumatoid arthritis. Rom J Intern Med 2019 ;57: 30-6.

3. Padjen I, Öhler L, Studenic P, Woodworth T, Smolen J, Aletaha D. Clinical meaning and implications of serum hemoglobin levels in patients with rheumatoid arthritis. Semin Arthritis Rheum 2017; 47: 193-8.

4. Goyal R, Das R, Bambery P. Serum transferrin receptor-ferritin index shows concomitant iron deficiency anemia and anemia of chronic disease is common in patients with rheumatoid arthritis in north India. Indian J Pathol Microbiol 2008; 51: 102-4.
5. Katchamart W, Narongroeknawin P, Chanapai W, Thaweeratthakul P, Srisomnuek A. Prevalence of and factors associated with depression and anxiety in patients with rheumatoid arthritis: A multicenter prospective cross-sectional study. Int J Rheum Dis 2020; 23: 302-8.

6. Abad VC, Sarinas PS, Guilleminault C. Sleep and rheumatologic disorders. Sleep Med Rev 2008; 12: 211-28.

7. Pehlivan S, Karadakovan A, Pehlivan Y, Onat AM. Sleep quality and factors affecting sleep in elderly patientswith rheumatoid arthritis in Turkey. Turk J Med Sci 2016; 46: 1114-21.

8. Sandikci SC, Colak S, Aydoğan Baykara R, et al. Evaluation of restless legs syndrome and sleep disorders in patients with psoriatic arthritis. Z Rheumatol 2019; 78: 987-95.

9. Ekbom K, Ulfberg J. Restless legs syndrome. J Intern Med 2009; 266: 419-31.

10. Gjevre JA, Taylor Gjevre RM. Restless legs syndrome as a comorbidity in rheumatoid arthritis. Autoimmune Dis 2013; 2013: 352782.

11. Urashima K, Ichinose K, Kondo H, Maeda T, Kawakami A, Ozawa H. The prevalence of insomnia and restless legs syndrome among Japanese outpatients with rheumatic disease: A cross-sectional study. PLoS One 2020; 15: e0230273.

12. Mustafa M, Bawazir Y, Merdad L, et al. Frequency of sleep disorders in patients with rheumatoid arthritis. Open Access Rheumatol 2019; 11: $163-71$.

13. Taylor-Gjevre RM, Gjevre JA, Nair BV. Increased nocturnal periodic limb movements in rheumatoid arthritis patients meeting questionnaire diagnostic criteria for restless legs syndrome. BMC Musculoskelet Disord 2014; 15: 378.

14. Ishaq M, Sualeh Muhammad J, Hameed K. Risk of restless legs syndrome in low socioeconomic rheumatoid arthritis patients. Mod Rheumatol 2013; 23: 705-8.

15. Villeneuve E, Nam J, Emery P. 2010 ACR-EULAR classification criteria for rheumatoid arthritis. Rev Bras Reumatol 2010; 50: 481-3.

16. Allen RP, Picchietti D, Hening WA, Trenkwalder C, Walters AS, Montplaisi J. Restless legs syndrome: diagnostic criteria, special considerations, and epidemiology. A report from the restless legs syndrome diagnosis and epidemiology workshop at the national institutes of health. Sleep Med 2003; 4: 101-19.

17. Walters AS, LeBrocq C, Dhar A, et al. Validation of the international restless legs syndrome study group rating scale for restless legs syndrome. Sleep Med 2003; 4: 121-32.

18. Beck AT, Ward CH, Mendelson M, Mock J, Erbaugh J. An inventory for measuring depression. Arch Gen Psychiatry 1961; 4: 561-71.

19. Beck AT, Epstein N, Brown G, Steer RA. An inventory for measuring clinical anxiety: psychometric properties. J Consult Clin Psychol 1988; 56: 893-7.

20. Valko PO, Bassetti CL, Bloch KE, Held U, Baumann CR. Validation of the fatigue severity scale in a Swiss cohort. Sleep 2008; 31: 1601-7.

21. Buysse DJ, Reynolds CF 3rd, Monk TH, Hoch CC, Yeager AL, Kupfer DJ. Quantification of subjective sleep quality in healthy elderly men and women using the Pittsburgh Sleep Quality Index (PSQI). Sleep $1991 ; 14: 331-8$.

22. Johns MWA. New method for measuring daytime sleepiness: the Epworth sleepiness scale. Sleep 1991; 14: 540-5.

23. Ware JE Jr, Sherbourne CD. The MOS 36-item short-form health survey (SF-36). I. Conceptual framework and item selection. Med Care 1992; 30: 473-83.

24. Muñoz M, García-Erce JA, Remacha ÁF. Disorders of iron metabolism. Part II: iron deficiency and iron overload. J Clin Pathol 2011; 64: 287-96.

25. Taylor-Gjevre RM, Gjevre JA, Skomro R, Nair B. Restless legs syndrome in a rheumatoid arthritis patient cohort. J Clin Rheumatol 2009; 15: 12-15.

26. Kucuk A, Uslu AU, Yilmaz R, Salbas E, Solak Y, Tunc R. Relationship between prevalence and severity of restless legs syndrome and anemia in patients with systemic lupus erythematosus. Int J Rheum Dis 2017; 20: 469-73.

27. Kunas RC, McRae A, Kesselring J, Villiger PM. Antidopaminergic antibodies in a patient with a complex autoimmune disorder and rapidly progressing Parkinson's disease. J Allergy Clin Immunol 1995; 96: 688-90.

28. Ballok DA, Earls AM, Krasnik C, Hoffman SA, Sakic B. Autoimmune-induced damage of the midbrain dopaminergic system in lupus-prone mice. J Neuroimmunol 2004; 152: 83-97.

29. Earley CJ, Connor JR, Beard JL, Malecki EA, Epstein DK, Allen RP. Abnormalities in CSF concentrations of ferritin and transferrin in restless legs syndrome. Neurology 2000; 54: 1698-700.

30. Connor JR, Wang XS, Allen RP, et al. Altered dopaminergic profile in the putamen and substantia nigra in restless leg syndrome. Brain 2009; 132: 2403-12. 
31. Hawkins RC. Total iron binding capacity or transferrin concentration alone outperforms iron and saturation indices in predicting iron deficiency. Clin Chim Acta 2007; 380: 203-7.

32. Wali S, Alsafadi S, Abaalkhail B, et al. The Association Between Vitamin D Level and Restless Legs Syndrome: A Population-Based Case-Control Study. J Clin Sleep Med 2018; 14: 557-64.

33. Kostoglou-Athanassiou I, Athanassiou P, Lyraki A, Raftakis I, Antoniadis C. Vitamin D and rheumatoid arthritis. Ther Adv Endocrinol Metab 2012; 3: 181-7.

34. Wali SO, Abaalkhail B, Alhejaili F, Pandi-Perumal SR. Efficacy of vitamin D replacement therapy in restless legs syndrome: a randomized control trial. Sleep Breath 2019; 23: 595-601.

35. Kapsimalis F, Richardson G, Opp MR, Kryger M. Cytokines and normal sleep. Curr Opin Pulm Med 2005; 11: 481-484.
36. Taylor-Gjevre RM, Gjevre JA, Nair BV, Skomro RP, Lim HJ. Improved Sleep Efficiency after Anti-Tumor Necrosis Factor a Therapy in Rheumatoid Arthritis Patients. Ther Adv Musculoskelet Dis 2011; 3: 227-33.

37. Lwin MN, Serhal L, Holroyd C, Edwards CJ. Rheumatoid Arthritis: The Impact of Mental Health on Disease: A Narrative Review. Rheumatol Ther 2020; 7: 457-71.

38. Isik A, Koca SS, Ozturk A, Mermi O. Anxiety and depression in patients with rheumatoid arthritis. Clin Rheumatol 2007; 26: 872-8.

39. Sevim S, Dogu O, Kaleagasi H, Aral M, Metin O, Camdeviren H. Correlation of anxiety and depression symptoms in patients with restless legs syndrome: a population based survey. J Neurol Neurosurg Psychiatry 2004; 75: 226-30. 